\title{
A invisibilidade das pessoas LGBTQIA+ nas bases de dados: novas possibilidades na Pesquisa Nacional de Saúde 2019?
}

\author{
The invisibility of the LGBTQIA+ people in the databases: \\ new possibilities in the 2019 National Health Research?
}

Angelita Alves de Carvalho (https://orcid.org/0000-0002-9342-4181) ${ }^{1}$

Rafael Chaves Vasconcelos Barreto (https://orcid.org/0000-0002-3570-6084) ${ }^{2}$
${ }^{1}$ Escola Nacional de Ciências Estatísticas, Instituto Brasileiro de Geografia e Estatística. R. André Cavalcanti 106, Centro. 20231-050 Rio de Janeiro RJ Brasil. litaacarvalho@yahoo.com.br

${ }^{2}$ Secretaria de Educação do Estado do Rio de Janeiro. Rio de Janeiro RJ Brasil.

\begin{abstract}
The availability of information about population minorities, in this case, the LGBTQIA+ population (Lesbians, Gays, Bisexual, Transvestite/Transsexual, Queer, Intersex, and Asexual), and the possible intersections with other variables on population bases is essential for understanding the similarities and specificities of the reality experienced by these groups, and the establishment of focused public policies. In this sense, this paper aims to reflect on the problems related to research about the sex and gender orientations/performances and, consequently, the lack of information on this topic available in population databases. From the inclusion of the question about sexual orientation in the 2019 National Health Survey database, despite the limitations, this paper presents possible opportunities for investigations on the topic from different perspectives.
\end{abstract}

Key words $L G B T Q I A+$ population, Data source, PNS 2019
Resumo A disponibilidade de informações a respeito das minorias populacionais, nesse caso, da população LGBTQIA+ (Lésbicas, Gays, Bissexuais, Travestis e Transexuais, Queers, Intersexuais e Assexuais) e a possibilidade de cruzamentos com demais variáveis em bases populacionais é imprescindivel para a compreensão das similaridades e especificidades da realidade vivenciada por estes grupos, bem como para a criação de politicas públicas focalizadas. Nesse sentido, buscamos refletir nesse artigo sobre os problemas relativos à investigação sobre as orientações/performances de sexo e gênero e, por consequência, a falta de informação sobre tal temática disponivel nas bases de dados populacionais. A partir da inclusão da pergunta sobre orientação sexual na base de dados da Pesquisa Nacional de Saúde (PNS), de 2019, apesar das limitações, apresentamos algumas das possiveis oportunidades de investigações sobre o tema a partir de diferentes óticas.

Palavras-chave População LGBTQIA+, Fonte de dados, PNS 2019 


\section{Introdução}

Quando pensamos em sexualidades dissidentes, ou seja, diferentes daquela caracterizada pela prática heterossexual, podemos pensar numa multiplicidade de comportamentos sexuais que diferem do esperado enquanto padrão pela sociedade. Em consequência disso, indivíduos que praticam/performam tais identidades, a saber, pessoas denominadas LGBTQIA+, vêm sendo invisibilizados por conta da discriminação existente contra eles.

O uso da sigla LGBTIA+ é, conforme relatam Soliva e Gomes Junior, uma escolha alinhada aos posicionamentos do Movimento LGBTQIA+ brasileiro contemporâneo, representando Lésbicas, Gays, Bissexuais, Travestis, Transexuais, Queers, Intersexo e Assexuais. Cabe aqui pontuar que tal sigla abarca identidades relacionadas à orientação sexual, qual seja, à atração afetivossexual por alguém de algum(ns) gênero(s) e que pode ser classificada como heterossexual, homossexual, bissexual, assexuais e pansexuais, foco de análise deste trabalho. Ao mesmo tempo que também contempla outras identidades como as de gênero, que é a forma como as pessoas se identificam ou se reconhecem e que inclui categorias como cisgênero, transgênero, transexual, bigênero, pangênero, drag queen, entre outros). Isso porque tal sigla objetiva a promoção, a inclusão e a visibilidade do maior número possível de pessoas com orientação sexual, identidade ou expressão de gênero (forma como a pessoa manifesta publicamente a sua identidade de gênero) desviantes do padrão cisheteronormativo e binário. Cabe ressaltar que esta sigla possui historicidade própria e é resultado dos debates ocorridos pelo próprio movimento, sendo sua forma atual um lugar de disputa tanto na militância como na academia, dividindo a opinião de pesquisadores, autores e militantes/ativistas ${ }^{1,2}$.

Essa população historicamente tem sido tratada sob os aspectos teológicos, morais ou mesmo médicos. Por exemplo, o termo homossexual surgiu em 1869, tendo sido definido pelo médico Karoly Maria Benkerdsua, e a abordagem do homossexualismo levou, por muitas décadas, à ideia da busca por causas e tratamentos para algo, até então, visto como uma patologia. A partir de muita luta do movimento LGBTQIA+, o uso desse termo vem sendo combatido desde a retirada pela Organização Mundial de Saúde, em 1990, da homossexualidade das listas de doenças na Classificação Internacional de Doenças ${ }^{3}$.
Falar de sujeitos LGBTQIA+ é perpassar por diversas intersecções de categorias como sexo, gênero, e sexualidade. Nesse ponto, Salih ${ }^{4}$ ressalta a interação das instituições, ou seja, da sociedade como um todo na determinação dessas categorias, em que a constituição do sujeito supõe que o sexo e o gênero são efeitos - e não causas - de instituições, discursos e práticas. Ou seja, nós, como sujeitos, não criamos ou causamos as instituições, os discursos e as práticas, mas eles nos criam ou causam, ao determinar nosso sexo, nossa sexualidade, nosso gênero (p. 21).

Diante do exposto, cabe aqui expor, como exemplo, a perspectiva do sujeito homossexual, como sendo aquele que possui não somente uma atração sexual por alguém do mesmo sexo, devendo ser levada em consideração sua perspectiva afetiva, fazendo com que a homossexualidade seja entendida como algo constituinte da identidade desse sujeito. Ser homossexual, nesse sentido, não se resume a transar com alguém do mesmo sexo, mas também permitir que haja um envolvimento emocional/afetivo ou mesmo adotar determinadas posturas que podem ir desde ao uso de determinado vocabulário - o pajubá ${ }^{5}$-, até a frequência a espaços de sociabilidade LGBTQIA+.

Apesar de alguns avanços em termos de aceitação e formulação de políticas públicas para a população LGBTQIA+, por todo o seu histórico de preconceitos e pela complexidade de tratar a questão de forma livre, a existência de dados dessa população ainda é rara. Ou seja, temos uma grande invisibilidade das questões relativas a esses sujeitos perante a sociedade. Essa invisibilidade se reflete na inexistência, até o momento, de pesquisas de âmbito nacional que considerem a inclusão de variáveis capazes de quantificar e qualificar esses sujeitos. Essas informações são imprescindíveis não somente para conhecer $o$ perfil desta população, mas, sobretudo, levantar suas necessidades e desenvolver políticas públicas eficazes.

Partindo dessas justificativas, este artigo busca refletir sobre os problemas relativos à investigação sobre tal temática em inquéritos populacionais e, por consequência, a falta de perguntas sobre orientação sexual disponível nas bases de dados de representação nacional. Com a inclusão da pergunta de orientação sexual na base de dados da Pesquisa Nacional de Saúde 2019 faz-se algumas discussões acerca das possibilidades de novas investigações, em especial da relação deste grupo com a saúde sexual e reprodutiva e homofobia. 


\section{A variável orientação sexual em pesquisas quantitativas}

$\mathrm{O}$ ato de autodeclarar a orientação sexual a alguém, quando esta difere da heterossexual, não é algo simples em um país sabidamente homofóbico/bifóbico/transfóbico, podendo ser considerado um ato político. Investigar essa questão em pesquisas domiciliares, em virtude disso, não é uma tarefa fácil. Isso porque, segundo Judith Butler ${ }^{6}$, quando alguém afirma sua homossexualidade, por exemplo, seja publicamente ou diretamente a alguém, essa mensagem não chega ao interlocutor como uma simples descrição desse sujeito, mas de seus atos enquanto homossexual, da sua prática. Acredita-se que este, quando revela sua orientação sexual, realiza o [ato] que descreve", pois "constituem o enunciado como conduta homossexual (p.180).

Durante muitos anos e ainda hoje, em algumas situações, tanto a homossexualidade quanto a bissexualidade são escondidas por parte dos indivíduos pertencentes a esses grupos, em muitos casos, como forma de se proteger e, para com isso poderem exercer suas demais identidades, fugindo do estigma que isso representa. Butler ${ }^{6}$ nos mostra, trazendo a homossexualidade como exemplo, que a renúncia pública dela poderia compensar a ameaça pública de um ato público de autodefinição homossexual (p.193). No entanto, a autora questiona que o sujeito que outrora afirma sua homossexualidade, mas posteriormente a nega, estaria por sua vez negando seus atos, mas não estaria negando seu desejo.

Além disso, o medo da interpretação que a declaração da homossexualidade/bissexualidade venha a ter pode inclusive levar muitos homens à recusa em responder uma pergunta que envolva sua orientação sexual, elevando, por exemplo, as taxas de não resposta a estas perguntas. Barreiras para se intensificar são bem conhecidas nos casos de procura por serviços de saúde, em especial aqueles ligados à testagem e aconselhamento no campo das Infecções Sexualmente Transmissíveis (ISTs), dado o medo de julgamentos morais ou mesmo serem associados a populações tidas como grupos de risco ou terem impacto negativo na qualidade da assistência ${ }^{7}$ (p. 2).

Posta essa dificuldade, a adoção do termo Homens que fazem Sexo com outros Homens (HSH), vem sendo adotado como forma de aproximar homens que mantém relações sexuais com outros homens e que não se identificam com o universo homoafetivo. A adoção desse termo poderia ser uma opção para esse tipo de pergunta nas bases de dados. Contudo, como destacado por Carrara e Simões ${ }^{8}$, tal definição busca ir além da escala identitária, facilitando a realização de políticas públicas sem que indivíduos sejam excluídos por não estarem - ou não se sentirem inseridos em determinada identidade.

Nesse mesmo sentido, como forma de se mitigar a subnotificação em pesquisas, resultante de uma possível não declaração da orientação sexual, podem ser utilizadas outras possibilidades de abordagem como a inclusão de variáveis que perguntem se o sujeito manteve relações com pessoas do mesmo sexo nos últimos doze meses. Tal perspectiva deslocaria a prática da autoidentificação à determinada identidade. Ressaltamos aqui que tal variável não indicaria que esse sujeito seria homossexual ou bissexual, visto que esta se trata de uma categoria identitária. Pode-se ainda lançar mão de outras nomenclaturas como os termos gay/lésbica, como forma de se prevenir possíveis falhas nas respostas em virtude de um possível desconhecimento dos demais termos, mas a adoção desses termos e autodeclação por parte do informante perpassam pelo reconhecimento deste enquanto sujeito pertencente a esta identidade sexual.

Dito isso, imagina-se a existência de um grande receio dos produtores de estatísticas públicas em incluírem em seus inquéritos nacionais perguntas relativas à temática sobre orientações/ performances relacionadas a sexo e gênero. Tanto isso é verdade que não temos no Brasil nenhuma variável deste tema nas principais pesquisas domiciliares do país, tais como Censo Demográfico, Pesquisa Nacional por Amostra de Domicílios Contínua (PNADC), Pesquisa de Orçamento Familiar (POF) etc. A primeira pesquisa de abrangência nacional que, embora não utilize a variável orientação sexual, incluiu a possibilidade de se encontrar uma parte desses sujeitos, foi a Contagem Populacional de 2007, na qual o Instituto Brasileiro de Geografia e Estatística (IBGE) incluiu a variável cônjuge de mesmo sexo. Através dessa variável é possível verificar aqueles casais de mesmo sexo que revelam estar em uma relação estável. Essa variável se manteve no Censo Demográfico de 2010 e, embora possa se considerar um avanço no sentido de entender esses sujeitos sob a perspectiva dos novos arranjos familiares, dentre outros desdobramentos, deixa de fora a possibilidade de pesquisar os demais sujeitos que vivem sua orientação de forma diferente da heterossexual.

Por fim, destaca-se, que de forma inédita, a Pesquisa Nacional de Saúde (PNS), de 2019, in- 
cluiu uma pergunta sobre o tema no bloco $\mathrm{Y}$ acerca de Atividade Sexual para maiores de 18 anos, qual seja: "Y8. Qual é sua orientação sexual?" com possibilidade de resposta: heterossexual, bissexual, homossexual, outro, não sabe, recusou-se. Esta pergunta por abarcar homens e mulheres abre uma grande possibilidade de investigações, uma vez que supera a limitação da informação sobre cônjuges do mesmo sexo, também presente na PNS. Assim, na próxima seção vislumbram-se algumas das diversas temáticas que podem ser exploradas sob a ótica da orientação sexual e podem trazer grandes contribuições para a área de estudos da população LGB. A adoção dessa sigla a partir desse momento do trabalho se dará uma vez que a variável investigada na PNS não possui a possibilidade de desagregação para as categorias de gênero travestis/transexuais e intersexuais.

\section{Algumas possibilidades de investigação na Pesquisa Nacional de Saúde (PNS) 2019 a partir da pergunta orientação sexual}

Por integrar uma pesquisa com foco nas condições de saúde da população um dos principais temas para serem explorados com a variável de orientação sexual é sua relação com a saúde dos indivíduos desse grupo. Para além das principais doenças crônicas, é possível analisar aspectos acerca da saúde sexual dos mesmos, uma vez que a PNS inclui tanto um bloco sobre doenças transmissíveis e outro acerca de relações sexuais e uso de preservativos. Estes se relacionam muito com estudos acerca da população LGB e são essenciais para se pensar programas dedicados à prevenção de Doenças Sexualmente Transmissíveis, como o Programa Nacional de DST/AIDS.

Atualmente, embora estejamos vivendo um período de desmonte de algumas políticas, não podemos deixar de citar avanços como a disponibilização da Profilaxia Pré-Exposição (PREP) para pessoas consideradas como vulneráveis ao contágio do HIV 9 . Segundo informações do Departamento de Doenças de Condições Crônicas e Infecções Sexualmente Transmissíveis (DCCI), são consideradas populações com risco de exposição frequente ao HIV: gays e outros homens que fazem sexo com homens; pessoas trans; trabalhadores(as) do sexo e parcerias sorodiscordantes (quando um dos parceiros é uma pessoa vivendo HIV). Tal escolha se dá por esses grupos concentrarem maior número de casos de HIV no país, devendo-se ainda ser necessário observar as práticas sexuais, as parcerias sexuais e os contextos específicos associados a um maior risco de in- fecçãa ${ }^{10}$ (p. 14). O conhecimento dessa realidade se deve à existência da variável orientação sexual nos levantamentos de notificações de casos de HIV disponibilizados pelo DATASUS.

No entanto, cabe refletirmos que a adesão à PREP, conforme apontam Barp e Mitjavila ${ }^{3}$, exige do sujeito que este se perceba enquanto pertencente a uma população vulnerável, ressignificando a antiga noção de grupo de risco como forma de poder retomar a liberdade sexual cerceada em decorrência da chegada do HIV.

Para além das questões relativas à saúde em si, outra temática de grande relevância é o perfil de acesso e utilização dos serviços de saúde bem como a qualidade da prestação dos serviços de saúde pela população LGB. Análises que explorem como o serviço de atenção primária e demais serviços de saúde vêm sendo utilizados e prestados a essa população são importantes, porque, como destacado por Lionço ${ }^{11}$, o discurso médico predominante sustenta a patologização de identidades e práticas sexuais socialmente discordantes da norma, o que legitima e reproduz processos discriminatórios. Ao mesmo tempo, segundo $\operatorname{Moscheta}^{12}$, a assistência à população LGBTQIA+ desafia os profissionais a desenvolverem ações de cuidado que superem a histórica abordagem estigmatizante, associada à própria construção dessas categorias identitárias como pertencentes ao rol de patologias pelo discurso médico-científico. Por fim, Rufino et al. ${ }^{13}$ e Mello et al. ${ }^{14}$ concluem que atuação médica em questões relativas às orientações/performances relacionadas a sexo e gênero se mostra limitada para $\mathrm{o}$ atendimento integral e humanizado em situações de violência sexual e saúde geral para a população LGBTQIA+. Isso porque o preconceito nos estabelecimentos de saúde e a invisibilidade entre os profissionais ocultaram ainda mais essa população, fazendo dos espaços para promover saúde locais incapazes de atender às reais necessidades da comunidade LGBTQIA+. Tendo conhecimento deste tratamento diferenciado do grupo temos a Política Nacional de Saúde Integral LGBT $^{15}$ que entre os seus objetivos está a análise da assistência prestada aos indivíduos desse grupo, no que tange ao acolhimento, à humanização e à integralidade da assistência.

Outro tema importante para a luta da população LGB é a homofobia, que pode ser analisada a partir do relato de vivências de diversos tipos de violência que esse grupo está exposto. Na PNS no módulo $\mathrm{V}$ foram investigados diversos tipos de violência para pessoas de 18 anos ou mais, bem como identificação do agressor e o local de 
ocorrência desta violência. A possibilidade desse tipo de análise é imprescindível para compreensão dos diversos tipos de vulnerabilidades que este grupo está exposto, bem como se fomentar e fortalecer as políticas de combate à homofobia, o sexismo e as violência de gênero em geral. Nesse sentido, Benevides e Nogueira ${ }^{16}$ nos revelam que, pertencer a um grupo socialmente excluído, como é o caso da população LGBTQIA+, é estar diariamente exposto ao ódio e à intolerância de todos aqueles que se julgam no direito de "discordar" das identidades sexuais e de gênero que fogem à norma cisgênero heterossexual.

Por fim, embora sem a pretensão de esgotar aqui a vasta multiplicidade de abordagens que a PNS possibilita, vislumbra-se ainda a possibilidade de estudos inéditos relacionando orientação sexual e estilo de vida dessa população. $\mathrm{O}$ módulo $\mathrm{P}$ da pesquisa traz aspectos relativos aos hábitos de alimentação, prática de atividade física, uso de bebidas alcoólicas e fumo. Inéditas também serão as análises do bloco $\mathrm{Z}$, que abarcam questões acerca da paternidade, como fecundidade masculina e adoção. Ambos os temas abrem uma grande agenda de pesquisa para a população LGB no Brasil.

\section{Reflexões finais}

Tem-se até o momento uma invisibilidade da população LGBTQIA+ nos inquéritos populacionais brasileiros, o que dificulta e limita a compreensão das similaridades e especificidades da realidade vivenciada por estes indivíduos, bem como a criação e sucesso de muitas das políticas públicas focalizadas existentes. Uma novidade que se propôs mostrar nesse artigo foi a inserção da variável orientação sexual na Pesquisa Nacional de Saúde 2019. Apesar de já terem sido disponibilizados os microdados do bloco Y da pesquisa, o IBGE ainda não divulgou essa variável, o que nos deixa apreensivos se o farão no futuro.
As possibilidades de investigações a partir da disponibilidade dessa informação na PNS podem ser diversas, como mostramos aqui. Uma corrente importante de estudos poderiam ser realizados na área da saúde, através de análises relativas ao perfil de saúde, em especial à saúde sexual da população LGB e ao acesso e utilização dos serviços de saúde por estes indivíduos, trazendo uma valiosa contribuição ao campo. Em paralelo, ainda poderiam ser realizados estudos relativos à ocorrência de violências e seus impactos para a saúde física e emocional desse grupo. Outro nicho de estudos, de caráter mais social e cultural, poderia ser realizado a partir da exploração da relação entre a orientação sexual e temas como estilo de vida e exercício da paternidade/maternidade. Ou seja, a disponibilidade dessa informação gera uma gama de oportunidades de investigações sobre a população LGB a partir de diferentes óticas e poderá servir de referência para ampliação de pesquisas que incluam essa variável em seus levantamentos.

Ressaltamos por fim que, apesar dos possíveis problemas de subdeclaração que possam conter essa estimativa bem como a manutenção da invisibilidade da população travesti e transexual por não conter variáveis que promovam a autodeclaração da identidade de gênero na pesquisa, a variável investigada na PNS 2019 será a única com representatividade nacional existente capaz de mensurar dados relativos à população LGB. Sendo, portanto, a liberação ao público desta informação por parte do IBGE uma grande contribuição no avanço dos estudos sobre as orientações/performances relacionadas a sexo e gênero dos brasileiros. Pois reforçamos a importância de se avançar neste tipo de investigação e que se busque ter variáveis que possam acolher a variedade de expressões e práticas, afim de que seus praticantes não sejam "rotulados" em uma ou outra palavra, permitindo que se compreenda de forma mais elástica a complexidade dessas escolhas, orientações, identidades e performances.

\section{Colaboradores}

Os autores participaram igualmente em todas as etapas de elaboração do artigo. 


\section{Referências}

1. Soliva TB, Gomes Junior J. "Entre Vedetes E "homens Em Travesti”: um estudo sobre corpos e performances dissidentes no Rio de Janeiro na primeira metade do século XX (1900-1950). Locus 2020; 26(1):123-148.

2. Jesus JG. Orientações sobre identidade de gênero: conceitos e termos. Guia técnico sobre pessoas transexuais, travestis e demais transgêneros, para formadores de opinião. 2a Ed., Brasília; 2012.

3. Barp LFG, Mitjavila MR. O reaparecimento da homossexualidade masculina nas estratégias de prevenção da infecção por HIV: reflexões sobre a implementação da PrEP no Brasil. Physis [Periódico na internet]. 2020; 30(3) [acessado 2020 ago 14]. e300319. Disponível em: https://doi.org/10.1590/S0103-73312020300319

4. Salih S. Judith Butler e a Teoria Queer. Tradução de Guacira Lopes Louro. Belo Horizonte: Autêntica Editora; 2018.

5. Libi F, Vip A. Aurélia, a dicionária da língua afiada. São Paulo: Editora da Bispa; 2006.

6. Butler J. Lenguaje, poder e identidad. Madrid: Síntesis; 2004.

7. Santos LES, Fontes WSantos, Oliveira AKS, Lima HO, Silva ARV, Machado ALG. O acesso ao Sistema Único de Saúde na percepção de homossexuais masculinos. Rev Bras Enferm 2020; 71(2).

8. Carrara S, Simões JA. Sexualidade, Cultura e Política: a trajetória da identidade homossexual masculina na antropologia brasileira. Cadernos Pagu 2007; (28):6599.

9. Brasil. Ministério da Saúde (MS). Secretaria de Políticas de Saúde. Coordenação Nacional de DST e Aids. Protocolo clínico e diretrizes terapêuticas para Profilaxia Pré-exposição (PrEP) de risco à infecção pelo HIV. Brasília: MS; 2017.

10. Brasil. Ministério da Saúde (MS). Secretaria de Políticas de Saúde. Coordenação Nacional de DST e Aids. Protocolo clínico e diretrizes terapêuticas para Profilaxia Pré-exposição (PrEP) de risco à infecção pelo HIV. Brasília: MS; 2017.
11. Lionço T. Que direito à saúde para a população GLBT? Considerando direitos humanos, sexuais e reprodutivos em busca da integralidade e da equidade. Saude Soc 2008; 17(2):11-21.

12. Moscheta MS. Responsividade como recurso relacional para a qualificação da assistência a saúde de lésbicas, gays, bissexuais, travestis e transexuais [tese]. Ribeirão Preto: Universidade de São Paulo; 2011.

13. Rufino A. C, Madeiro AP, Girão MJ. O ensino da sexualidade nos cursos médicos: a percepção de estudantes do Piauí. Rev Bras Educ Med 2013; 37(2):178-185.

14. Mello L, Perilo M, Braz CA, Pedrosa C. Políticas de saúde para lésbicas, gays, bissexuais, travestis e transexuais no Brasil: em busca de universalidade, integralidade e equidade. Sex Salud Soc 2011; (9):7-28.

15. Brasil. Ministério da Saúde (MS), Secretaria de Gestão Estratégica e Participativa. Departamento de Apoio à Gestão Participativa. Política Nacional de Saúde Integral das Lésbicas, Gays, Bissexuais, Travestis e Transexuais. Brasília: MS; 2013.

16. Benevides BG, Nogueira SNB, organizadores. Dossiê dos assassinatos e da violência contra travestis e transexuais brasileiras em 2020. São Paulo: Expressão Popular, ANTRA, IBTE; 2021.

Artigo apresentado em 23/05/2021

Aprovado em 02/06/2021

Versão final apresentada em 04/06/2021

Editores-chefes: Maria Cecília de Souza Minayo, Romeu Gomes, Antônio Augusto Moura da Silva 